\title{
TENTOONSTELLING: IN DE BAN VAN DE KRIS
}

Al eeuwen lang worden mensen gefascineerd door de kris. Niet alleen in Azië maar ook in het Westen roept de kris bij sommigen reacties en zelfs emoties op. Reeds in 1624 beeldde Rembrandt een Javaanse kris af op zijn schilderij 'Samson en Delila'. Deze kris was waarschijnlijk uit Java meegenomen door een VOC-dienaar. De eerste krissen die in Europa hun intrede deden, zijn nauw verweven met de zoektochten naar specerijen die sinds het eind van de $16^{\mathrm{e}}$ eeuw vanuit Spanje, Portugal en Nederland werden ondernomen. In die tijd was de kris in Europa vooral een exotisch fenomeen. In de Indonesische archipel is van oudsher de magische kracht die aan dit wapen wordt toegeschreven een onuitputtelijke bron van wonderbaarlijke verhalen. Daarnaast wordt het vakmanschap waarmee een kris is vervaardigd hoog gewaardeerd. Indonesië Museum Nusantara in Delft toont tot en met 27 mei 2007 meer dan 120 objecten in de tentoonstelling 'De kris, bewierookt, gekoesterd en gevreesd'. De keuze voor een tentoonstelling over de kris werd mede ingegeven door diverse verzoeken vanuit het publiek. Velen kennen de verhalen over de magie en de kracht van de kris zoals die in beeld gebracht werden in de televisieserie uit $1977^{\prime}$ De kris Pusaka' met Willem Nijholt in de hoofdrol. Misschien kan een krissententoonstelling ons wat dichter bij die kris pusaka brengen, of wordt het mysterie alleen maar groter?

\section{De kris pusaka}

Een kris kan binnen een familie een heilig erfstuk (pusaka) zijn dat van generatie op generatie wordt doorgegeven. In dit wapen zouden krachten van de voorouders schuilen die de eigenaar bescherming bieden en geluk brengen. De kris heeft echter ook zijn krachten verkregen door de hand van de meestersmid of empu, die door vasten, bidden en offeren en vooral door zijn vakmanschap het magische wapen creëerde naar de wensen van de opdrachtgever.

Een kris is herkenbaar als pusaka wanneer bekend is wie de oorspronkelijke bezitter of maker was. Ook is het van belang dat er een element uit het verleden aan gekoppeld is, bijvoorbeeld een door een priester opgeschreven formule, of een mondelinge overlevering. Het is niet mogelijk om een echte pusaka van iemand te kopen. Pusaka's worden geschonken of geërfd en ze moeten bij de nieuwe eigenaar passen.

Over het algemeen worden pusaka krissen van een vorst als het meest krachtig beschouwd. Ze hebben vaak een eigen naam beginnend met Kyai, een aanduiding van eerbied en respect.

Een kris pusaka heeft in de loop der tijd in het Indonesische denken zijn kracht bewezen. Zo kan een kris de eigenaar onkwetsbaar maken, dapperheid schenken, geluk brengen in de handel, beschermen tegen ziekte enzovoort. Om deze kracht te beheersen en te danken voor deze beschermingee access 


\section{Afbeelding 1}

Krisdrager met kris, gepolychromeerd hout, Bali, inv.nr.BL 24-1

Een kris is een zeer gekoesterd bezit dat met de grootst mogelijke zorg wordt behandeld. Om de kris 20 goed mogelijk te bewa. ren en er mee te pronken, wordt hij op Bali en Lombok soms in een krisdrager geplaatst. Krisdragers kunnen verschillende vormen hebben, meestal zijn het figuren uit de wayangverhalen. Maar ook andere onderwerpen zoals kikkers, dikbuikige Chinezen of kinderen zijn geliefd. Deze krisdrager stelt een staand jongetje voor dat opkijkt naar de kris die hij in beide handen houdt. Het kindje heeft het Downsyndroom. Deze kinderen worden op Bali beschouwd als bijzondere wezens die in verbinding staan met de bovenwereld. Hij staat op een prachtig voetstuk met bloemmotieven en een vogeltje. Ook de bijbehorende kris is van hoge kwaliteit.

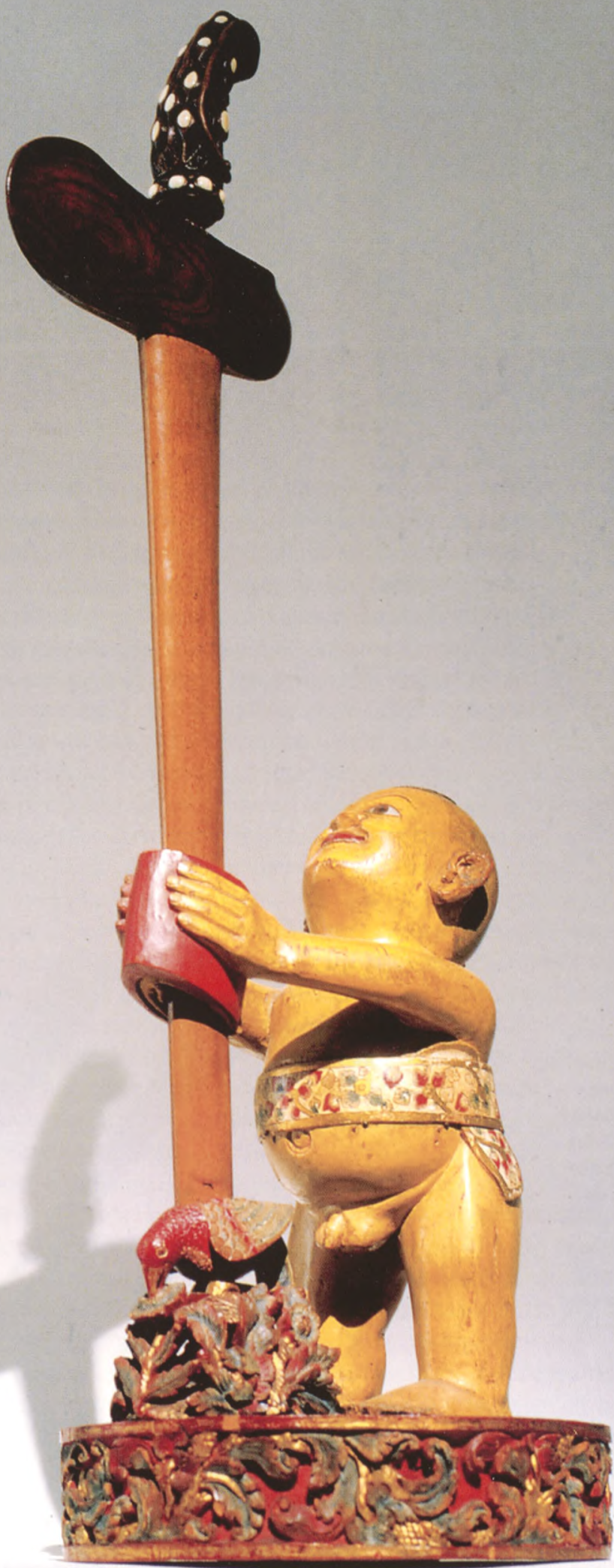




\section{Afbeelding 2 (boven)} Kris, ijzer, goud en robijnen, Sulawesi of Maleisie, inv.nr. $S_{3472}$ Oude pronkkris uitgevoerd in een goud. legering. Het schip van de kris (wrangka) heeft prachtig, verfijnd filigrain-werk. De gedetailleerde motieven op de schede zijn in goud gedreven. Dergelijke kostbare krissen waren beslist geen gemeengoed. In Maleisië mochten alleen leden van een vorstenhuis gouden krissen dragen. Vaak behoorde dit type kris tot de vorstelijke regalia.

De overschede of pendok, heeft het model van een Bugis-kris uit Zuid-Sulawesi, met de lus op de wrangka. Het lemmet heeft 1 luk (bochten). De gouden greep is in de vorm van een papegaai met robijnen oogjes. De kris is in de museumcollectie gekomen als zijnde afkomstig uit ZuidSulawesi. Zowel de vormgeving van de kris en met name de greep zijn echter Maleisisch. Waarschijnlijk is de kris in opdracht in Maleisie gemaakt voor een vorst in Zuid-Sulawesi. Ook huwelijksbanden tussen de twee gebieden kunnen een verklaring zijn voor het voorkomen van Maleisische krissen in Indonesie.

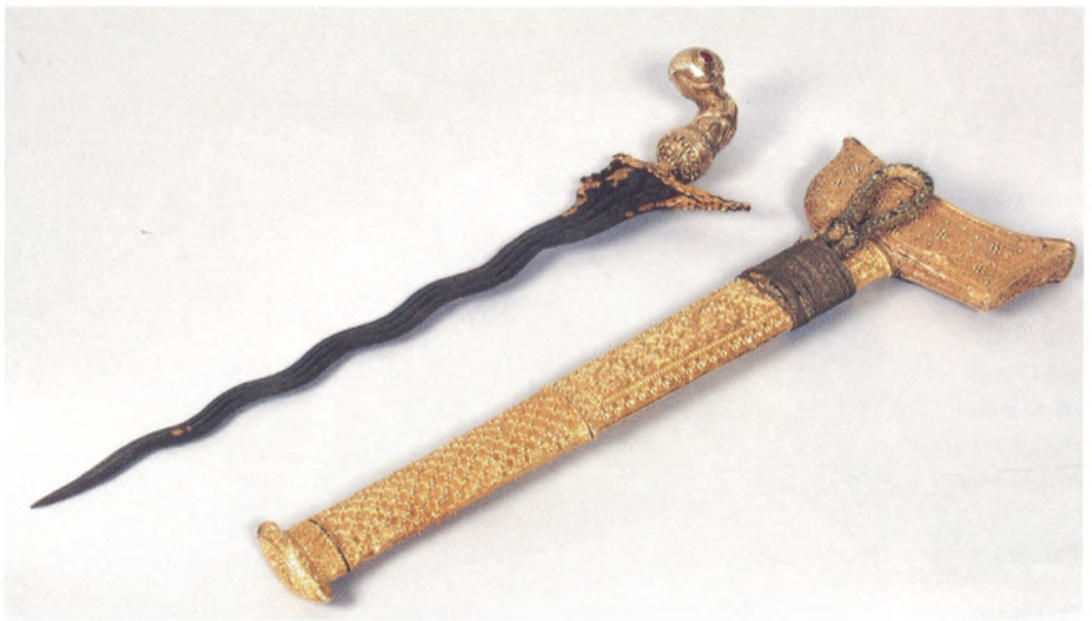

dienen op gezette tijden offers van wierook, bloemen en voedsel aan de kris pusaka te worden aangeboden. Daarnaast vindt regelmatig een rituele reiniging plaats met geurige oliën en wierook.

Het omgekeerde is echter ook mogelijk. Er zijn krissen die de eigenaar ongeluk lijken te brengen. Soms kan dit met rituelen en offers bezworen worden maar lukt dit niet dan wordt de kris doorgeschonken aan iemand bij wie de kris zich 'thuis' voelt. 
Afbeelding 3

Pronkkris, met inlegwerk van parelmoer, $45 \mathrm{~cm}$, Sumatra of Maleisie, inv.nr. S 527-53 Schitterende pronkkris met een greep van ivoor in de vorm van een papegaaienkopje. Het lemmet is recht met een duidelijke pamor-tekening. De overschede toont de rijkdom van deze kris; repen buffelhoorn ingelegd met parelmoer, waartussen weer reepjes ivoor. Evenals de gouden kris is cok deze waarschijn. lijk vervaardigd in Maleisiě. De kris zou afkomstig zijn van Sumatra's costkust. Hier waren eind $19^{\circ}$ eeuw diverse sultans die fortuin hadden gemaakt met de tabakteelt. Zij toonden hun rijkdom door dergelijke krissen te laten maken en deze als relatiegeschenk te geven aan onder andere Nederlandse bestuursambtenaren. Het zijn dus ware showstukken die niet zozeer de functie van familie-erfstuk hadden, maar de status van de schenker weer. spiegelden.
Op de tentoonstelling zijn verschillende kris pusaka te zien. Het zijn lang niet altijd fraai bewerkte, voorname krissen. Echte kris pusaka zijn soms relatief eenvoudig zoals de kris van Raden Martodikromo en de kris van Raden Mas Tjokro Adisoerio, oud-regent van Wonosobo. Opvallend is een kris pusaka waarvan de gehele schede is beschreven met informatie over de eigenaar, wie de empu was en de leeftijd van de kris. Een andere kris heeft als opschrift dat hij eigendom was van Bin Lalui, vermoedelijk een zeerover die in de tijd van de VOC actief was in de Indonesische wateren.

\section{De tedere schoonheid van de kris}

Het is onmogelijk om in een tentoonstelling een volledig overzicht te geven van alle stijlen en typen krissen die er zijn want elke kris is uniek. Als uitgangspunt hebben we gekozen voor het verhaal achter een specifieke kris. Aan de andere kant ligt de nadruk op de schoonheid en het vakmanschap waarmee de krissen zijn gemaakt.

Om een expositie van hoogwaardige kwaliteit te kunnen realiseren werden drie gerenommeerde krissenverzamelaars benaderd met het verzoek de museumcollectie te bekijken, suggesties te geven voor de inhoud van de tentoonstelling en objecten uit hun collectie in bruikleen te willen afstaan. Het resultaat van deze uitstekende samenwerking is terug te vinden op de tentoonstelling.

De oudste tentoongestelde krissen zijn de zogenaamde kris buda. Voor verzamelaars is de kris buda van veel belang omdat deze de negatieve krachten van andere krissen in een verzameling zou neutraliseren. Het zijn korte brede dolkachtige steekwapens waarvan de ouderdom gewoonlijk op de $8^{\mathrm{e}}$ eeuw wordt gesteld, omdat een dergelijk wapen ook in de Borobudur is aangetroffen. Wetenschappelijke bewijzen voor die datering zijn er nog niet, maar dit geldt ook voor de Majapahit-krissen, die weliswaar uit de Majapahit-tijd ( $14^{\mathrm{e}}$ eeuw) of eerder kunnen dateren maar die als type tot en met de $19^{\mathrm{e}}$ eeuw zijn vervaardigd. Ze hebben niet zozeer de functie van steekwapen maar zijn veeleer een amulet of talisman. Handvat en lemmet van deze krissen zijn uit één stuk gesmeed en de greep heeft gewoonlijk de vorm van een gestileerd, licht voorovergebogen mensfiguur. Andere amuletwapens zijn de kudi's, waarvan de oorsprong duidt op een oud landbouwwerktuig, en zogenaamde kris pijit, krissen die in het lemmet 'duimafdrukken' van de empu tonen. Deze zijn samen met de eerder genoemde pusaka-krissen op het eerste deel van de tentoonstelling te zien.

De tweede groep krissen op de tentoonstelling omvat die van de klassieke krissen van Java, Madura, Bali en Sumatra. De nadruk ligt hier op het technisch vakmanschap dat weerspiegeld wordt in de pamors van het lemmet (het dooreen smeden van diverse ijzer- en nikkellegeringen), en de vaak kostbare aankleding van de kris. Bijzondere zeldzame houtsoorten zijn voor de schede en greep gebruikt. Dit hout geeft de krissen niet alleen een voorname schoonheid, maar ook een magische kracht die aan bepaalde gevlekte houtsoorten wordt toegekend. Niet zelden zijn materialen als been, schelp, ivoor, olifantskies en edelmetaal toegepast om een meerwaarde aan de kris te geven. De oude en kostbare krissen spreiden de kracht en pracht van de familiestukken op soms indrukwekkende wijze ten toon.

Zeer bijzonder zijn de zeldzame krissen afkomstig uit gebieden buiten Java: Noord- en West- Sumatra, Zuid-Sulawesi, Borneo, Maleisië en de Filippijnen. Uit Gayo-Alas in Noord-Sumatra, een berggebied dat grenst aan Aceh endatcess 
beroemd is om zijn traditionele zilversmeedkunst, getuigen de krissen van een strijdvaardige islamitische cultuur. Het Minangkabau-gebied in WestSumatra is per traditie een rijke streek. Door de bijzondere sociale structuur, het matriarchaat, bleven familiebezittingen eeuwenlang binnen de verwantengroep bewaard. Enkele oude en zeer fraaie krissen roepen het beeld op van een lange familiegeschiedenis. Zeer zeldzaam is een kris uit Nias, een eiland ver uit de kust van Noordwest-Sumatra. Hoewel men hier oorspronkelijk geen krissen kende, is mogelijk een bestaand Sumatraans lemmet verwerkt tot een geheel eigen kris, met een greep van olifantskies en een schede die typisch is voor andere wapens van Noord-Nias.

Indrukwekkend zijn de krissen en krisgrepen uit Pattani (noordgrens Maleisië / Thailand) met de karakteristieke greep in de vorm van een vogelachtige figuur met een lange snavel. Over de juiste betekenis van deze vogelfiguur bestaan verschillende theorieën. Een ervan luidt dat deze oorspronkelijk Garuda voorstelde, een mensfiguur met een vogelkop. Garuda is het rijdier van de hindoegod Wisnu. Door de steeds sterker wordende invloed van de islam zou de mens op de achtergrond zijn geraakt terwijl de vogelkop sterker geprofileerd werd en de snavel steeds grotere vormen aannam.

De zeldzaam oude krissen met hun vervaarlijke lemmet uit de Filippijnen en uit Noord-Borneo vallen op door hun grote formaat en de subtiele greep die de vorm heeft van een papegaaienkopje.

De museumcollectie is in alle onderdelen vertegenwoordigd met de nadruk op pronkkrissen zoals de gouden vorstenkris uit Maleisië en een spectaculaire kris van ivoor en been met als greep een papegaaienkopje met robijnen oogjes. Uit eigen collectie komen ook een kris met een zeer bijzonder pamor uit Bali, die alleen gedragen mocht worden door leden van de kaste der Brahmanen en een Balische kris met 25 luk (bochten). De krisdragers van Bali en Lombok nemen een speciale plaats in, niet alleen vanwege hun uiterlijk, maar vanwege hun soms bewogen geschiedenis. Zo zijn de twee krisdragers uit Lombok tijdens de Lombok-expeditie in 1894 door een Nederlandse soldaat mee naar Nederland genomen. Dat ze slachtoffer van de strijd zijn geweest is duidelijk te zien. Bij de ene is de hand afgehouwen en bij de andere zijn neus.

De tentoonstelling wordt afgesloten met enkele moderne krissen, waarvan één zelfs met een gouden schede, die laten zien dat het vakmanschap in Indonesië nog steeds bestaat.

Krissen zijn niet alleen een fenomeen uit het verleden, maar spelen in het hedendaagse Indonesië nog steeds een belangrijke rol. Hoe deze rol nu is, is te zien op een documentaire uit 2006, die aan het begin van de tentoonstelling wordt vertoond. De film is ter beschikking gesteld door Garuda TV, de Indonesische televisiezender in Nederland.

- 'De kris, bewierookt, gekoesterd en gevreesd'

Indonesië Museum Nusantara

St. Agathaplein 4-5

2611 HR Delft

www.nusantara-delft.nl

Bij de tentoonsteiling is een kleine publicatie voor euro 2 te verkrijgen in de museumwinkel. 